\title{
Efficacy of a bioactive alloplast, in the treatment of human periodontal osseous defects-a clinical study
}

\author{
Rajiv Subbaiah ${ }^{1}$, Biju Thomas ${ }^{2}$
}

${ }^{1}$ Currently-Senior lecturer, Rajarajeswari Dental College and Hospital, Ramohalli cross, Kumbulgodu, Mysore road, Bangalore

${ }^{2}$ Currently-Professor and Head, Department of Periodontics, A.B.Shetty, Memorial Institute Of Dental Sciences, Deralakatte, Mangalore, Karnataka, India

Correspondence:

No.76, Vinayaka Layout 2nd stage,

Vijayanagar, Bangalore-560040,

Karnataka, India

subbaiahrajiv@rediffmail.com

Received: 08/02/2010

Accepted: 26/08/2010

\author{
Subbaiah R, Thomas B. Efficacy of a bioactive alloplast, in the treatment \\ of human periodontal osseous defects-a clinical study. Med Oral Patol \\ Oral Cir Bucal. 2011 Mar 1;16 (2):e239-44. \\ http://www.medicinaoral.com/medoralfree01/v16i2/medoralv16i2p239.pdf \\ Article Number: $16816 \quad$ http://www.medicinaoral.com/ \\ (C) Medicina Oral S. L. C.I.F. B 96689336 - pISSN 1698-4447 - eISSN: 1698-6946 \\ eMail: medicina@medicinaoral.com \\ Indexed in: \\ Science Citation Index Expanded \\ Journal Citation Reports \\ Index Medicus, MEDLINE, PubMed \\ Scopus, Embase and Emcare \\ Indice Médico Español
}

\begin{abstract}
Presently, bone replacement grafts are one of the modalities of therapy for which there is histologic evidence of regeneration coronal to the base of the previous osseous defect. Bioactive glasses are used extensively in medicine and dentistry.

This study evaluated the additional efficacy of a bioactive alloplast, PerioGlas, in comparison with open flap debridement only. 8 systemically healthy volunteers were chosen, each having 2 collateral sites with $\geq 6 \mathrm{~mm}$ clinical probing depth and radiographic evidence of an intrabony defect. Randomly, one defect was treated with open flap debridement plus bioactive glass (test) and the other with open flap debridement alone (control). At baseline, 3, 6, 9 months measurements were recorded which included plaque index, gingival index, pocket probing depth, clinical attachment level, and increase in gingival recession. Standardized radiographs were used to measure defect fill and alveolar crest resorption. The data were subjected to statistical analysis. Both treatments showed no significant differences between the two groups at any point of time. However, radiographically, bioactive glass group showed significant improvement in bone fill over the sites treated with open flap debridement alone. The alloplastic bone graft material, PerioGlas, demonstrated clinical advantages beyond that achieved by debridement alone.
\end{abstract}

Key words: Bone replacement grafts, alloplast, bioactive glasses, PerioGlas, intrabony defect, soft tissue parameters, radiographically.

\section{Introduction}

The pathological hallmark of periodontitis is the destruction of the supporting structures of the teeth involved. The advent of regenerative approaches in contemporary periodontics has increased patient's treatment options and enhanced the long- term prognosis of many teeth that have advanced periodontal destruction.
At the present time, bone replacement grafts are the only modality of therapy for which there is histologic evidence, in humans, of regeneration of new attachment composed of new bone, cementum and periodontal ligament coronal to the base of the previous osseous defect. This has not been observed with other forms of regenerative periodontal therapy, which attempt to eliminate 
bony defects without a bone replacement graft material (1).

The bioactive glasses have been used extensively in medicine for middle ear surgery and have been applied to dentistry in the treatment of bone defects, ridge preservation and periodontal bone defects. Bioactive ceramics have been used clinically to repair bone defects owing to their biological affinity to living bone; i.e. the capability of direct bonding to living bone, their so-called bioactivity. (2)

During periodontal therapy, deep intraosseous defects represent a major challenge for the clinician, often requiring access by flap surgery alone or in association with bone-regenerative procedures. This study was designed to evaluate the additional efficacy of a bioactive alloplast, namely PerioGlas, in comparison with open flap debridement only.

\section{Materials and Methods}

\section{Subject selection criteria}

8 volunteers aged between 20-65 years, with at least two collateral osseous defects were selected from those reporting to the out patients' department of A.B. Shetty Memorial Institute of Dental Sciences, Deralakatte, Mangalore.

Inclusion criteria

1 Two or more sites showing periodontal osseous defects in different quadrants with pocket probing depth $\geq 6 \mathrm{~mm}$.

2 No medical problems that contraindicated routine periodontal surgery.

3 Patients who had not taken antibiotics within 6 months of initial examination.

4 No periodontal surgery in the areas to be treated within the last 12 months.

5 No known allergy to materials and drugs used or prescribed in this study, including silica products.

\section{Exclusion criteria}

1 Subject has a medical condition or therapeutic regimen that would decrease the probability of soft tissue and bone healing.

2 Pregnant patients.

3 Smokers.

4 Patients with previously implanted materials, natural or synthetic and physical barriers in the selected defects.

5 Patients who did not show any improvement in oral hygiene after phase I therapy.

6 Patients who did not accept the terms and conditions of the study.

\section{Data Collection}

All participants, following an initial examination and treatment planning appointment, were given detailed instructions in plaque control measures and were then subjected to full mouth scaling and root planing. A split mouth model was employed in this study. 2 of the bilateral defects were randomly chosen as Site A - test (open flap debridement with PerioGlas) or Site B - control (open flap debridement only).

Postoperatively, subjects were prescribed antibiotic 100mg Doxycycline, and analgesic Brufen 400mg. Patients were instructed to rinse with $10 \mathrm{ml}$ of $0.2 \%$ chlorhexidine gluconate twice daily.

The following parameters were recorded at baseline, 3 months, 6 months and 9 months.

1 Plaque index - Silness \& Loe, 1964 (3).

2 Gingival index - Loe \& Silness, 1963 (4).

3 Probing pocket depth - measured from the crest of the gingival margin to the base of the pocket.

4 Clinical attachment level - Measured from cementoenamel junction to the base of pocket.

5 Recession - Measured from the fixed reference point to the gingival margin.

6 Standardised radiographs of the experimental and control sites were taken using a paralleling technique with a film holder. This was taken to measure the bone fill and the alveolar crest resorption.

\section{Soft Tissue Parameters}

Using the apical margin of the customized acrylic stent as the fixed reference point (FRP) the following measurements were made at the proximal line angle of the tooth with the associated bony defect. Only one site representing the same deepest point of the defect was included.

The following measurements were recorded for test and control teeth by a single investigator using a Williams graduated periodontal probe.

1 Stent (FRP) to Cementoenamel junction (CEJ)

2 Stent (FRP) to gingival margin (GM)

3 Stent (FRP) to base of the pocket (BOP)

The following calculations were made from the clinical measurements recorded:

1 Pocket Depth $=($ FRP to BOP $)-($ FRP to GM $)$

2 Clinical attachment level $=($ FRP to BOP $)-($ FRP to $\mathrm{CEJ})$

3 Increase in gingival recession $=(\mathrm{FRP}$ to $\mathrm{GM}$ at recall interval) - (FRP to GM at baseline).

These measurements were made at baseline, 3 months, 6 months and 9 months.

Radiographic / hard tissue parameters :

Standardized intra oral periapical radiographs of each defect site using parrelling cone technique with film holders (XCP kit) and a millimeter grid (X-ray mesh) were taken, preoperatively and post-operatively at 3 months, 6 months and 9 months. Radiographic evaluation was performed on an X-ray viewer (Fig. 1 and 2).

Bone defect depth was measured preoperatively and post-operatively at 3 months, 6 months and 9 months as the distance from the alveolar crest to the base of the bone defect. 


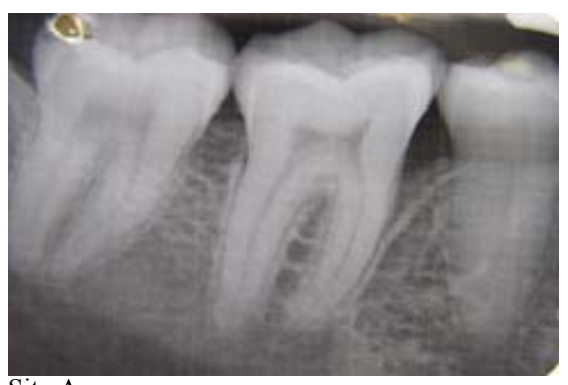

Site A

Fig. 1. Site A: Baseline, Site B: Baseline.

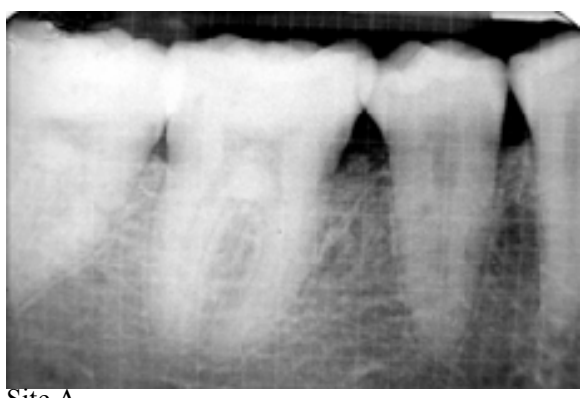

Fig. 2. Site A: 9 months, Site B: 9 months.

The Base of defect (BOD) was defined as the most coronal point where the periodontal ligament space showed continuous width. (5)

The alveolar crest (AC) level was taken as the crossing of the alveolar crest with the root surface. (5)

If several bony contours could be identified, the most apical that crossed the root was defined as BOD and the most coronal as the AC. (6)

The following calculations were made from the radiographs:

Amount of defect fill $=$ Initial defect depth - defect depth at recalled time interval.

Percentage $(\%)$ of defect fill = Amount of defect fill $/$ baseline defect depth $\mathrm{x} 100$. These measurements were made at baseline, 3 months, 6 months and 9 months.

Statistical analysis

The obtained data were then subjected to statistical analysis. The Mann-Whitney U test was used to compare the results between site A (test) and site B (control) groups. The Wilcoxon sign rank sum test was used to compare the results between the various time intervals.

\section{Results}

The plaque index, gingival index, probing depth showed no statistical difference between any of the test and control sites at any point of time. Similarly, clinical attachment level and gingival recession (Table 1) showed no statistical difference between any of the test and control

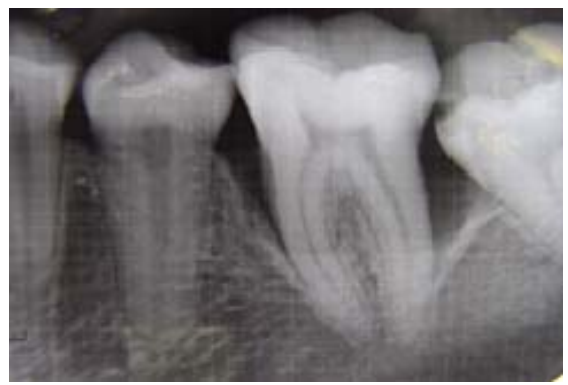

Site B

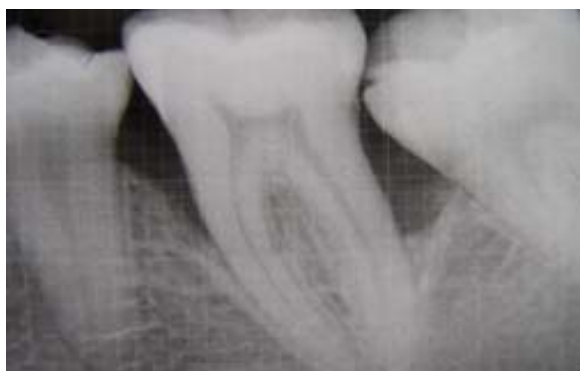

Site B

sites at any point of time. However, the bone fill (Table 2 and Fig. 3 ) and crestal bone resorption showed differences.

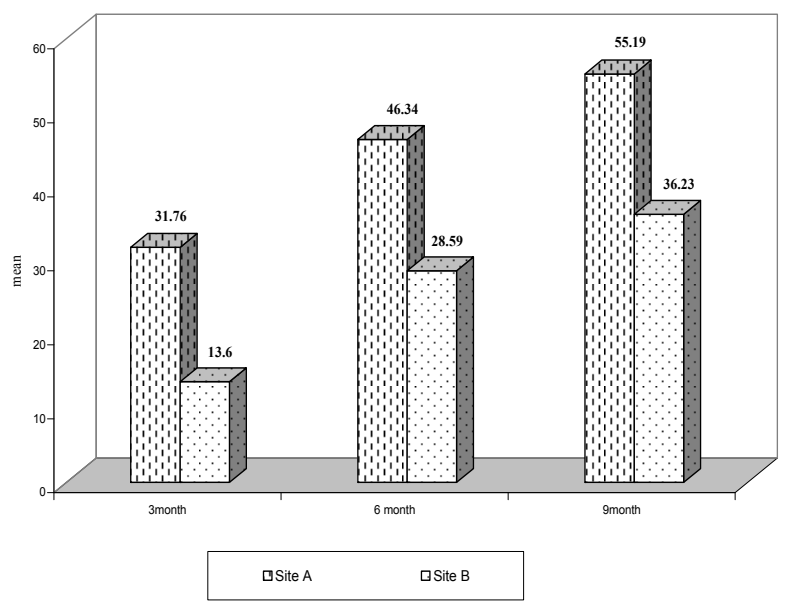

Fig. 3. Comparison of mean percentage bone fill between Site A and Site B. 
Table 1. Comparison of (PD), (CAL) and increase in gingival recession between test (Site A) and control (Site B) site at baseline, 3,6, and 9 months.

\begin{tabular}{|c|c|c|c|c|c|}
\hline & SITE & $\mathbf{N}$ & MEAN & $\begin{array}{c}\text { STD. } \\
\text { DEVIATION }\end{array}$ & $Z$ test \\
\hline \multirow{2}{*}{ PD Baseline } & A & 8 & 8.5000 & 1.4142 & 0.1070 \\
\hline & $\mathrm{B}$ & 8 & 8.2500 & 1.5811 & $\mathrm{p}=0.914 \mathrm{~ns}$ \\
\hline \multirow{2}{*}{ PD 3 months } & A & 8 & 5.6250 & 1.3025 & 0.7550 \\
\hline & B & 8 & 6.3750 & 1.8468 & $\mathrm{p}=0.45 \mathrm{~ns}$ \\
\hline \multirow{2}{*}{ PD 6 months } & A & 8 & 4.5000 & 0.9258 & 1.3610 \\
\hline & B & 8 & 5.6250 & 1.5980 & $\mathrm{p}=0.174 \mathrm{~ns}$ \\
\hline \multirow{2}{*}{ PD 9 months } & A & 8 & 4.2500 & 1.0351 & 1.3510 \\
\hline & B & 8 & 5.1250 & 1.3562 & $\mathrm{p}=0.177 \mathrm{~ns}$ \\
\hline \multirow{2}{*}{ CAL Baseline } & A & 8 & 7.6250 & 2.6693 & 0.05400 \\
\hline & B & 8 & 7.3750 & 2.3867 & $\mathrm{p}=0.957 \mathrm{~ns}$ \\
\hline \multirow{2}{*}{ CAL 3 months } & A & 8 & 6.2500 & 2.7124 & 0.6380 \\
\hline & B & 8 & 7.2500 & 2.6592 & $\mathrm{p}=0.524 \mathrm{~ns}$ \\
\hline \multirow{2}{*}{ CAL 6 months } & A & 8 & 4.8750 & 2.9001 & 1.2720 \\
\hline & B & 8 & 7.0000 & 1.7255 & $\mathrm{p}=0.204 \mathrm{~ns}$ \\
\hline \multirow{2}{*}{ CAL 9 months } & A & 8 & 4.5000 & 3.2950 & 1.1700 \\
\hline & B & 8 & 6.5000 & 2.6186 & $\mathrm{p}=0.242 \mathrm{~ns}$ \\
\hline \multirow{2}{*}{$\begin{array}{l}\text { Increase in gingival } \\
\text { recession at } 3 \text { months }\end{array}$} & A & 8 & 0.3750 & 0.51755 & 1.1200 \\
\hline & B & 8 & 0.7500 & 0.70711 & $\mathrm{p}=0.263 \mathrm{~ns}$ \\
\hline \multirow{2}{*}{$\begin{array}{l}\text { Increase in gingival } \\
\text { recession at } 6 \text { months }\end{array}$} & A & 8 & 0.5000 & 0.53452 & 1.72 \\
\hline & B & 8 & 1.0000 & 0.53452 & $\mathrm{p}=0.085 \mathrm{~ns}$ \\
\hline \multirow{2}{*}{$\begin{array}{l}\text { Increase in gingival } \\
\text { recession at } 9 \text { months }\end{array}$} & A & 8 & 0.5000 & 0.53452 & 1.20 \\
\hline & B & 8 & 0.8750 & 0.64087 & $\mathrm{p}=0.328 \mathrm{~ns}$ \\
\hline
\end{tabular}

ns- not significant.

Table 2. Inter-group comparison of percentage bone fill between test site (site A) and control site (site B) at 3 months, 6 months and 9 months.

\begin{tabular}{|l|c|c|c|c|c|}
\hline Time interval & Site & $\mathbf{N}$ & Mean & $\begin{array}{c}\text { Std. } \\
\text { Deviation }\end{array}$ & $\mathbf{Z}$ test \\
\hline At 3 months & A & 8 & 31.763 & 20.885 & 1.96200 \\
& B & 8 & 13.600 & 15.256 & $\mathrm{p}=0.05 \mathrm{sig}$ \\
\hline At 6 months & A & 8 & 46.338 & 15.725 & 1.98500 \\
& B & 8 & 28.588 & 15.725 & $\mathrm{p}=0.049 \mathrm{sig}$ \\
\hline At 9 months & A & 8 & 55.188 & 15.900 & 2.01200 \\
& B & 8 & 36.225 & 15.796 & $\mathrm{p}=0.046$ sig \\
\hline
\end{tabular}

sig- significant. 


\section{Discussion}

Loss of alveolar bone is one of the characteristic signs of destructive periodontal disease and is generally considered to represent the anatomical sequela to the apical spread of periodontitis. (7) To be considered as a regenerative modality, a material or technique must histologically demonstrate that bone, cementum and a functional periodontal ligament can be formed on a previously diseased root surface. Bone grafts and their synthetic substitutes have been used in an attempt to gain this therapeutic endpoint. (8)

This study compared the soft tissue and hard tissue changes with the use of flap debridement along with alloplastic bone graft material, PerioGlas, versus that of open flap debridement alone in periodontal intrabony osseous defects. 8 systemically healthy patients were chosen with bilateral defects for this 9 month study.

Case selection is particularly important to the use and success of bone replacement grafts. The patient must be highly motivated and demonstrate the ability to effectively remove bacterial plaque from every surface of every tooth on a daily basis. Likewise, the patient's age, health and emotional status, social habits such as smoking and tolerance for lengthy dental appointments are important considerations. Some studies used test sites in one subject while the control in the other. (9) In order to nullify the subject differences, bilateral defects in the same patient were chosen and randomly divided into test and control.

The plaque and gingival indices showed non-significant differences between the test and control groups. The results could be due to the lack of improvement in home care. This is similar to the findings of Zamet et al. (10) who observed no significant change in plaque index or gingival index 12-months postsurgery compared to baseline. An overall improvement in the probing depth and attachment level was noted in both test and control groups. The probing depth in test and control group at any time interval showed no statistical difference. A study of longer duration (12 months) was conducted by Froum et al. (11). They compared the repair response of bioactive glass synthetic bone graft particles and open flap debridement. Comparable values to the present study were observed at 9 months.

The increase in gingival recession showed no statistical difference between test and control sites at any time interval. The increase in gingival recession between various time intervals was significant in test group. Park et al. (9) and Lovelace et al. (12) showed lesser recession values, probably due to the fact that these studies were of shorter duration (6 months).

While measuring all the soft tissue parameters a fixed reference point at the apical edge of the custom made acrylic stent was used. Clark et al. (13) have reported that the measurements using a stent appear to be bet- ter than the measurements made using cemento-enamel junction as the reference point. However, Trevor Watts (14) examined the possible sources of error with regard to probing measurement reliability with and without stent. He found that the stent made little difference to overall reproducibly of probing depths, though it appears to reduce variation in different areas.

Healing of the bone defect was a combination of bone fill and alveolar crest resorption. The percentage of bone fill was significant at 3,6 and 9 months. At the test site the values obtained at various intervals are statistically significant. The results of the present study are in general agreement with the findings of Zamet et al. (10) in their clinical comparison of intrabony defects treated with bioactive glass or open flap debridement. The CADIA analysis indicated greater radiographic density and volume in bioactive glass treated sites. The conclusion that bioactive glass treated sites showed a greater trend to improvement compared to open flap debridement treated sites is consistent with the findings of the present study. The crestal resorption was minimal at the end of 9 months which is much lesser than that observed in the study by Froum et al. (11). This could be due to the fact that Froum et al conducted a longer follow up study (12 months). Also, there was a clinical re-entry which was done at the end of their study, which could have resulted in better observation of the site.

A change of the alveolar bone level was detected radiographically using consecutive radiographs. Projection geometry of serial radiographs should be standardized to minimize measurement errors. A source of error is caused by different angulations between the central beam related to the film holder and the film while relation between teeth and film is fixed. (15) Another source of projection artifacts is angulation differences between the central beam and the anatomic structures to be imaged. (16) Prefabricated film holders like what was used in this study may provide projection standardization to a certain degree.

The selection of the appropriate imaging technique cannot overcome the fundamental limitations of intraoral radiography, even when the images are of high quality. Several studies have demonstrated that intraoral radiographs tend to underestimate the amount of bone loss, whereas, radiographic assessment of severe osseous destruction was shown to overestimate actual bone loss. The use of radio-opaque or transparent millimeter grids, does not improve the measurement accuracy. (17) Grids like the one used in this study may facilitate the measurement process, but they do not account for magnification or distortion.

There were some difficulties encountered in the radiographic analysis because bioactive ceramics have radioopacity very similar to bone, which made the height measurement somewhat problematic. 
The treatment success reported in various studies may differ which is likely to be in part to the varying morphology of initial defects. In this study, some defects were 3-wall defects, while others were 1-wall or a combination of 1-2 walls. It has been reported that 2- and3wall defects have the highest potential for regeneration when grafting procedures are used. In addition, the defects varied according to depth and width, with the aforementioned study reporting better predictability with deep, narrow defects versus shallow, wide ones. It is hard to control these variables in a clinical investigation, but the potential effects of this variability on the results need to be realized. However, even in the best of circumstances, it is impossible to find matched osseous defects. Randomization may help to control this variable.

Within the limits of this study, the following conclusions can be drawn.

- There were no differences in probing depth reduction, gain in clinical attachment level and increase in gingival recession between the two groups.

- The sites treated with bioactive glass showed significant improvement in bone fill over the sites treated with open flap debridement alone. Both groups showed significant improvements at the various time intervals.

- The alveolar crest resorption showed significant difference between the two groups. The control group showed significant difference at the recall intervals but the test group did not.

- Bioactive glass was well tolerated by the gingival tissues.

- Further studies with a larger sample size are required to clarify the beneficial effects of bioactive glass in treating periodontal intrabony defects.

The results of the present study are consistent with Garrett's assessment that "in controlled clinical trials treating furcation defects and intraosseous defects, non-absorbable and absorbable synthetic graft materials have consistently demonstrated clinical advantages beyond that achieved by debridement alone." (18)

\section{References}

References with links to Crossref - DOI

1. Yukna RA. Synthetic bone grafts in periodontics. Periodontol 2000. 1993;1:92-9.

2. Ohtsuki C, Kamitakahara M, Miyazaki T. Bioactive ceramicbased materials with designed reactivity for bone tissue regeneration. J R Soc Interface. 2009;6 Suppl 3:S349-60.

3. Silness J, Loe H. Periodontal disease in pregnancy. II. Correlation between Oral hygiene and periodontal condtion. Acta Odontol Scand. 1964;22:121-35.

4. Loe H, Silness J. Periodontal disease in pregnancy. I. Prevalence and Severity. Acta Odontol Scand. 1963;21:533-51.

5. Benn DK. A computer-assisted method for making linear radiographic measurements using stored regions of interest. J Clin Periodontol. 1992;19:441-8.

6. Eickholz P, Benn DK, Staehle HJ. Radiographic evaluation of bone regeneration following periodontal surgery with or without expanded polytetrafluoroethylene barriers. J Periodontol. 1996;67:379-85.
7. Papapanou PN, Tonetti MS. Diagnosis and epidemiology of periodontal osseous lesions. Periodontol 2000. 2000;22:8-21.

8. Rosen PS, Reynolds MA, Bowers GM. The treatment of intrabony defects with bone grafts. Periodontol 2000. 2000;22:88-103.

9. Park JS, Suh JJ, Choi SH, Moon IS, Cho KS, Kim CK, et al. Effects of pretreatment clinical parameters on bioactive glass implantation in intrabony periodontal defects. J Periodontol. 2001;72:730-40.

10. Zamet JS, Darbar UR, Griffiths GS, Bulman JS, Brägger U, Bürgin W, et al. Particulate bioglass as a grafting material in the treatment of periodontal intrabony defects. J Clin Periodontol. 1997;24:410-8.

11. Froum SJ, Weinberg MA, Tarnow D. Comparison of bioactive glass synthetic bone graft particles and open debridement in the treatment of human periodontal defects. A clinical study. J Periodontol. 1998;69:698-709.

12. Lovelace TB, Mellonig JT, Meffert RM, Jones AA, Nummikoski PV, Cochran DL. Clinical evaluation of bioactive glass in the treatment of periodontal osseous defects in humans. J Periodontol. 1998;69:1027-35.

13. Clark DC, Chin Quee T, Bergeron MJ, Chan EC, Lautar-Lemay C, de Gruchy K. Reliability of attachment level measurements using the cementoenamel junction and a plastic stent. J Periodontol. 1987;58:115-8.

14. Watts T. Constant force probing with and without a stent in untreated periodontal disease: the clinical reproducibility problem and possible sources of error. J Clin Periodontol. 1987;14:407-11.

15. Sewerin I, Andersen V, Stoltze K. Influence of projection angles upon position of cementoenamel junction on radiographs. Scand $\mathrm{J}$ Dent Res. 1987;95:74-81.

16. Zappa U, Simona C, Graf H, Van Aken J. In vivo determination of radiographic projection errors produced by a novel filmholder and an x-ray beam manipulator. J Periodontol. 1991;62:674-83.

17. Mol A. Imaging methods in periodontology. Periodontol 2000. 2004;34:34-48.

18. Garrett S. Periodontal regeneration around natural teeth. Ann Periodontol. 1996;1:621-66. 